\title{
Biomechanical Characterization of Ascending Aortic Aneurysms
}

\author{
Marija Smoljkić • Heleen Fehervary - Philip Van den Bergh • \\ Alvaro Jorge-Peñas • Louis Kluyskens • Steven Dymarkowski • \\ Peter Verbrugghe - Bart Meuris • Jos Vander Sloten • Nele Famaey
}

Received: date / Accepted: date

\begin{abstract}
Ascending thoracic aortic aneurysms (ATAA) are a silent disease, ultimately leading to dissection or rupture of the arterial wall. There is a growing consensus that diameter information is insufficient to assess rupture risk, whereas wall stress and strength provide a more reliable estimate. The latter parameters cannot be measured directly and must be inferred through biomechanical assessment, requiring a thorough knowledge of the mechanical behaviour of the tissue. However, for healthy and aneurysmal ascending aortic tissues, this knowledge remains scarce.
\end{abstract}

This study provides the geometrical and mechanical properties of the ATAA of six patients with unprecedented detail. Prior to their ATAA repair, pressure and diameter were acquired non-invasively, from which the distensibility coefficient, pressure-strain modulus and wall stress were calculated. Uniaxial tensile tests on the resected tissue yielded ultimate stress and stretch values. Parameters for the Holzapfel-Gasser-Ogden material

M. Smoljkić · H. Fehervary · P. Van den Bergh · A. Jorge-Peñas · J. Vander Sloten $\cdot$ N. Famaey

Biomechanics Section,

Department of Mechanical Engineering, KU Leuven

Celestijnenlaan 300, b2419

Leuven, Belgium

Tel.: +32 16372824

E-mail: nele.famaey@kuleuven.be

L. Kluyskens · P. Verbrugghe $\cdot$ B. Meuris

Clinical Cardiac Surgery,

Department of Cardiovascular Sciences,

KU Leuven, Leuven, Belgium

S. Dymarkowski

Translational MRI,

Department of Imaging and Pathology,

KU Leuven, Leuven, Belgium model were estimated based on the pre-operative pressure-diameter data and the post-operative stress-stretch curves from planar biaxial tensile tests.

Our results confirmed that mechanical or geometrical information alone cannot provide sufficient rupture risk estimation. The ratio of physiological to ultimate wall stress seems a more promising parameter. However, wall stress estimation suffers from uncertainties in wall thickness measurement, for which our results show large variability, between patients but also between measurement methods. Our results also show a large strength variability, a value which cannot be measured non-invasively. Future work should therefore be directed towards improved accuracy of wall thickness estimation, but also towards the large scale collection of ATAA wall strength data.

Keywords Ascending aortic aneurysm · Material properties · Planar biaxial testing · In vivo pressurediameter measurements · Rupture risk

\section{Introduction}

Among cardiovascular diseases, which are the leading cause of death in Europe (Nichols et al, 2012), ascending thoracic aortic aneurysms are perceived as a 'silent killer' with $95 \%$ of the incidents not diagnosed until complications such as dissection or rupture occur (Elefteriades et al, 2015). An aortic aneurysm is a permanent dilatation of the aorta of at least 1.5 times its expected diameter. This dilatation is a consequence of an irreversible pathological weakening of the aortic wall caused by a degenerative process described in Martufi et al (2014). 
Currently, elective surgical repair is the only treatment for aortic aneurysms, but this surgical intervention includes high risks and an absolute benefit cannot be guaranteed. Two criteria are clinically used to estimate the rupture risk of the aorta and to evaluate the risk-to-benefit ratio for a possible intervention. The geometry criterion urges aneurysm repair if the ascending thoracic aortic aneurysm (ATAA) diameter exceeds the size of 55 $\mathrm{mm}$, and the growth rate criterion advises intervention in case of fast aneurysmal diameter expansion (i.e. $\approx 1$ $\mathrm{cm} /$ year) (Chau and Elefteriades, 2013).

However, according to Pape et al (2007), 60\% of the dissections in their study happened at diameters lower than $55 \mathrm{~mm}$, and $40 \%$ at diameters lower than $50 \mathrm{~mm}$. Indeed, several studies report that there is no correlation between the aneurysm size and the risk of rupture (Martin et al, 2013b Vorp et al, 2003). Besides this issue of the reliability of the geometry criterion, additional problems are related to the accuracy of the diameter measurements. The imaging techniques used in the standard clinical protocol do not distinguish between different phases of the cardiac cycle (Martin et al 2013b). This can lead to underestimation of the current maximal diameter (if the measurement was not performed at systole), or overestimation of the growth rate (if the previous measurement was captured close to diastole and the current close to systole). These errors significantly influence the diagnosis of the physician.

Several research groups have already suggested to use wall stress as a new predictor of the rupture risk for abdominal (Fillinger et al 2003, Venkatasubramaniam et al, 2004) and descending thoracic aortic aneurysms (Shang et al, 2013). However, the estimation of the in vivo peak stress is not as straightforward as the maximal diameter measurement, as it requires to solve the static (or perhaps even dynamic) mechanical equilibrium of the aortic wall in response to the in vivo loading situation. To date, this research has mostly been focused on abdominal aortic aneurysms (AAA). Gasser et al (2010) used nonlinear finite element (FE) analyses to successfully distinguish between ruptured and non-ruptured AAA based on an estimation of the peak wall stress and the peak wall rupture risk. To simplify and speed up computation, Joldes et al (2015) suggested an approach to estimate the wall stresses by using linear elastic FE computations that do not require any information on the actual material parameters. However, the latter approach is highly sensitive to the correct geometrical description, and hence suffers significantly from the current struggle to accurately estimate wall thickness and its distribution. An overview of the modelling studies of ATAA tissues up to December 2014 can be found in Martufi et al (2015). Recently, Trabelsi et al (2015) performed patient-specific FE analyses of five ATAA cases to estimate the wall stress at four different pressure levels and concluded that the peak wall stress was between $28 \%$ and $94 \%$ of the ATAA's failure strength. The location of the peak wall stress was at the inner curvature. In a follow-up study, Trablesi et al (2016) characterized material parameters of five human ATAAs in two ways: by means of an inverse method based on a gated CT scan and secondly by testing the excised tissue in a bulge-inflation test. The obtained parameters were used in a $\mathrm{FE}$ stress analysis to estimate the rupture risk.

The peak wall stress by itself is not a sufficient criterion to estimate rupture risk, since it has to be related to the patient-specific wall strength. Since the latter proves impossible to measure in vivo, large datasets of clinical cases of ruptured aneurysms, as well as in vitro tensile strength tests should be combined with statistical regression models to estimate patient specific wall strength. Multiple studies reported wall strength data for AAA, e.g. Raghavan et al (2011); Xiong et al (2008). However, only Vande Geest et al (2006) used multiple linear regression and mixed-effects modelling techniques to define a statistical model for a non-invasive estimation of local wall strength. The input data to the model were the thickness of the intraluminal thrombus, the normalized diameter, family history and gender. For ATAA, Vorp et al (2003); Iliopoulos et al (2009); García-Herrera et al (2012) and Trabelsi et al (2015) reported wall strength of in total 82 cases. Out of these, only Trabelsi et al (2015) combined this information to in vivo patient data. Krishnan et al (2015) derived in vivo patient specific isotropic hyperelastic material properties of ATAA from cyclic aortic wall strain measured with DENSE-MRI. These properties were used to estimate the peak wall stress at diastolic and systolic pressure by means of $\mathrm{FE}$ analysis. In their case, ex situ mechanical experiments were not performed, so no strength data could be obtained.

This manuscript provides detailed clinical and mechanical data on six ATAA patients who underwent elective surgery repair. Apart from general health information and preoperative blood pressure and dynamic CT imaging, the in vivo aortic diameter, the blood pressure and the aortic wall thickness were measured intra-operatively. Following surgical resection, the aneurysmal tissue was tested 
mechanically in uniaxial and planar biaxial test setups. Subsequent data analysis yielded several parameters commonly used in literature as well as nonlinear anisotropic material parameters. The following section elaborates on the data acquisition and presents the different biomechanical characterization methods used in this study. The results section provides a representative extract of all data. In the final section, a critical interpretation of these results is combined with a discussion on the next steps to be taken towards a more reliable assessment of ATAA rupture risk.

\section{Materials and Methods}

\subsection{Data acquisition}

\subsubsection{Patient info}

Six patients were operated at Gasthuisberg University Hospital (UZ Leuven, Belgium) between October and November 2013. The study was approved by the UZ Leuven Ethical Committee. For all but one patient, surgery was executed before the aortic size reached the critical diameter of $55 \mathrm{~mm}$, due to confounding factors such as a bicuspid aortic valve (BAV) or severe coronary artery disease. In the latter case, the coronary artery bypass grafting was needed so the aneurysm repair was a concomitant cardiac surgery. An overview of relevant patient data is provided in Table [1. As detailed below, data was collected pre-operatively, intra-operatively, as well as ex situ on the resected tissue.

\subsubsection{Pre-operative}

ECG-gated time-resolved CT-scans (Somatom Definition Flash system; Siemens Healthcare, Forchheim, Germany) were taken over a cardiac cycle for each patient. Patients were injected with $70 \mathrm{~mL}$ iomide (flow rate of $4 \mathrm{~mL} / \mathrm{s}$ ), followed by $30 \mathrm{~mL}$ of saline solution. At the cost of a slightly higher radiation dose, this imaging technique allows precise determination of the time point during the cardiac cycle at which the scan was taken. CT-images were made at 21 phases of the cardiac cycle. Each phase contains ca. 600 transverse slices.

From these scans, the maximal outer diameter at the belly of the aneurysm was measured. This was done manually using a standard DICOM viewer, by an experienced surgeon. The process was repeated for the 21 phases of the cardiac cycle, resulting in a diameter-phase curve for every patient.
Systolic and diastolic pressures were measured auscultatorily at the time of the CT-scan. In order to derive the pressure evolution over the cardiac cycle, aortic pressure waveforms were reproduced using a cardiovascular simulator as described in Ferrari et al (2012); Fresiello et al (2014). The simulator uses a lumped parameter model including a representation of the left and the right heart according to the Frank-Starling mechanism and pulmonary and systemic circulation according to the Windkessel model. The additional model inputs, besides pressures, were the heart rate, the body weight and the height of each patient.

The obtained pressure-phase curve was manually synchronized to the diameter-phase curve by matching the maximal diameter to the maximal pressure and minimizing the hysteresis in the pressure-diameter loop.

\subsubsection{Intra-operative}

During surgery, before resection, an epiaortic echocardiography probe was placed directly on the belly region of the aneurysm wall, on the anterior side, 3 to $5 \mathrm{~cm}$ above the aortic valve (at the level of the maximal diameter). A sample image can be seen in Figure 17a. By synchronizing these images to the simultaneously obtained ECG signal, the in vivo wall thickness at systolic and diastolic pressure were derived during post-processing. Three separate wall thickness measurements were averaged at each pressure level. Considering the image contrast properties and location of the probe, these measurements represent the thickness of the intimal and the medial layer of the aortic wall (IMT).

\subsubsection{Ex situ}

After aneurysm resection, a ring-shaped specimen was cut from the belly region of the patients' ATAA and fresh frozen in phosphate-buffered saline at $-80^{\circ} \mathrm{C}$. Histological slices of $5 \mu \mathrm{m}$ were stained with hematoxylin and eosin. Mosaic pictures (see Figure $1 \mathrm{~b})$ of the slices were microscopically obtained (MosaiX, Axiovision, Zeiss, Germany). The intima-media thickness (IMT) (dark pink area on Figure 1p) was measured on 20 locations along the whole sample and then averaged using an open source image processing program ImageJ.

Prior to mechanical testing, the specimens were slowly defrosted over night, at $+4^{\circ} \mathrm{C}$. Next, they were cut into square- and dogbone-shaped samples for planar biaxial and uniaxial testing, respectively 
Table 1 Summary of the six patients examined in this study. $\mathrm{d}_{i}^{\text {dia }}$ and the $\mathrm{d}_{i}^{\text {sys }}$ are the inner aortic diameter at diastole and systole. $\mathrm{P}^{d i a}$ and $\mathrm{P}^{\text {sys }}$ are the diastolic and systolic blood pressure, respectively. BMI stands for the body mass index. LDL is the low density lipoprotein cholesterol, also referred to as 'bad cholesterol'. Aortic size index (ASI) was calculated as $\mathrm{d}_{i}^{\text {sys }}$ divided by the body surface area Davies et al (2006). BAV stands for a bicuspid aortic valve and CAGB for a coronary artery bypass grafting. The patients' labels refer to the gender ( $\mathrm{M}$ - male or $\mathrm{F}$ - female) and the age in years.

\begin{tabular}{ccccccc}
\hline & $\mathrm{d}_{i}^{\text {dia }}-\mathrm{d}_{i}^{\text {sys }}$ & $\mathrm{P}^{\text {dia }}-\mathrm{P}^{\text {sys }}$ & $\begin{array}{c}\mathrm{BMI} \\
{[\mathrm{mm}]}\end{array}$ & $\begin{array}{c}\mathrm{LDL} \\
{\left[\mathrm{mg} / \mathrm{m}^{2}\right]}\end{array}$ & $\begin{array}{c}\text { ASI } \\
{[\mathrm{mg} / \mathrm{dL}]}\end{array}$ & Comment \\
{$\left[\mathrm{cm}^{2} \mathrm{~m}^{2}\right]$} & \\
\hline F74 & $58.5-62.1$ & $70-143$ & 37.5 & 126 & 3.30 & BAV \\
F68 & $49.3-51.0$ & $99-149$ & 26.0 & 68 & 2.74 & BAV \\
M58 & $46.6-51.2$ & $65-135$ & 30.7 & 77 & 2.63 & CABG \\
M60 & $43.8-45.6$ & $84-135$ & 34.9 & 104 & 2.04 & BAV \\
M52 & $43.3-45.5$ & $80-117$ & 24.4 & 144 & 2.39 & BAV \\
M55 & $38.9-41.4$ & $73-144$ & 30.6 & 84 & 2.07 & \\
\hline
\end{tabular}

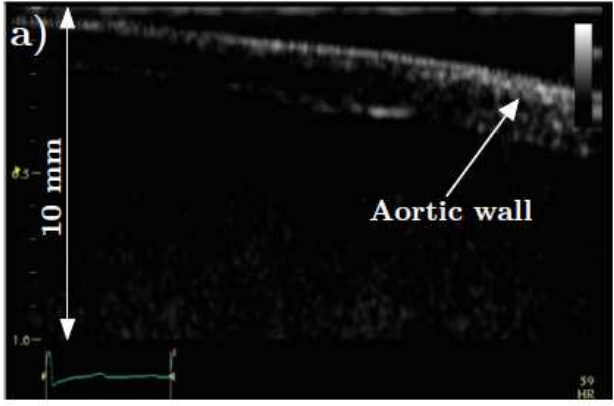

b)
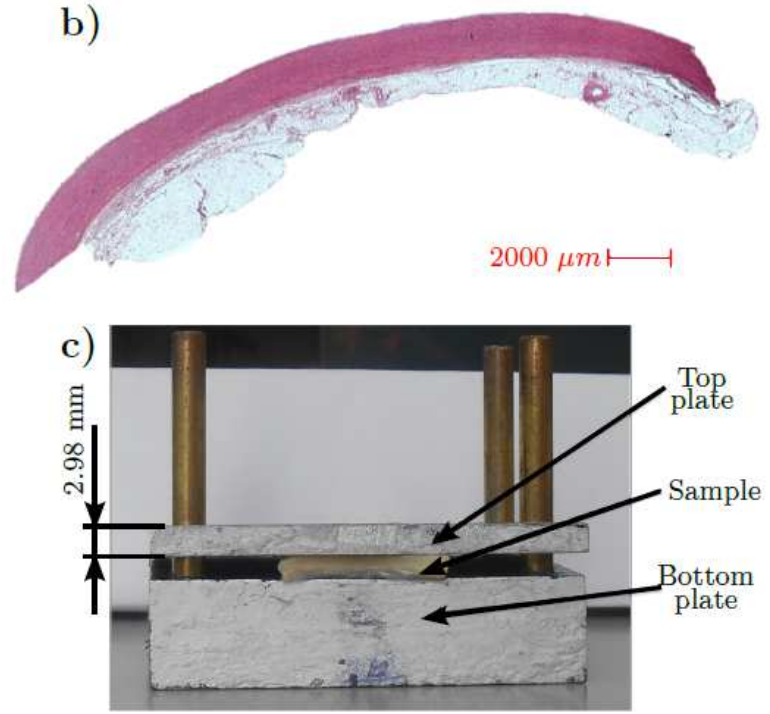

Fig. 1 Different types of thickness measurements: a) in vivo epiaortic echocardiography, b) ex situ histological measurements and c) ex situ measurement prior to the uniaxial and planar biaxial testing.

(Figure 2). The intima-media-adventitia thickness (IMAT) of the samples was measured optically by placing them between two calibrated metal plates and performing image analysis in Matlab ${ }^{\circledR}$ (Figure 1 1 .). The dogbone samples were $12 \mathrm{~mm}$ in length on average with a $2 \mathrm{~mm}$ width in the neck region. For each patient, minimally one sample in the axial and one sample in the circumferential direction was prepared and tested. The biaxial samples were
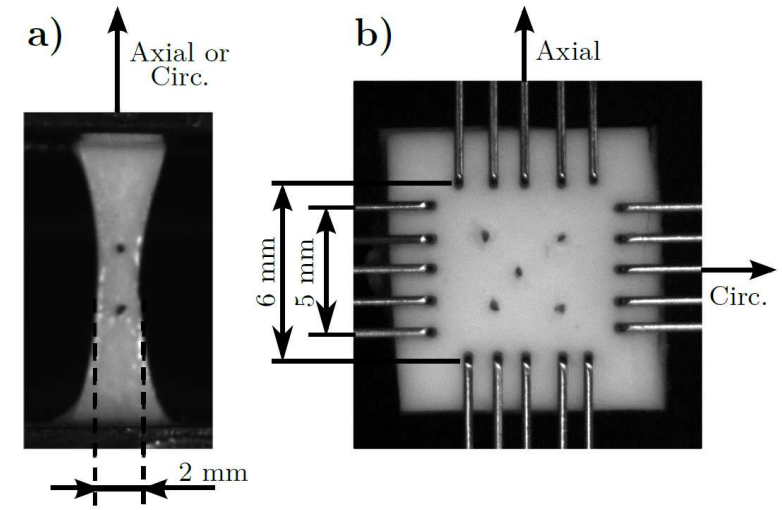

Fig. 2 A sample example with markers attached for a) uniaxial and b) planar biaxial mechanical testing. Circ. stands for the circumferential direction.

mounted on a planar biaxial setup using rakes, with the axial and the circumferential axes of the sample aligned with the testing axes of the setup, Figure $2 \mathrm{p}$. The size covered by the rakes was 6 by $6 \mathrm{~mm}$.

On each biaxial sample, five markers were glued in the central region (Fig. 2p). For the uniaxial samples, two markers were used (Fig. 2a). Small fragments of surgical suture wire were used as markers and marker tracking was performed using in-house developed software in Matlab ${ }^{\circledR}$. However, in the case of uniaxial tests, the displacements of the clamps were used for strain calculations due to the marker tracking problems caused by insufficient lighting conditions during the test.

The dogbone-shaped samples were tested uniaxially with an Instron $\AA 5943$ testing device (Instron, Norwood, USA). Small pieces of sand paper were placed at the sample edges to reduce a chance of slippage. Three to five samples per patient were tested. A displacement-controlled protocol was used with ten preconditioning cycles (up to $8 \%$ strain) followed by stretch until failure.

Planar biaxial tests were performed on a BioTester 5000 (CellScale, Waterloo, Canada). Samples were submerged in the physiological solution which was 
heated at $37^{\circ} \mathrm{C}$. Three to six samples per patient were tested. A physiologically relevant testing protocol was derived by estimating the in vivo circumferential force, strain and loading rate. For this estimation, the aneurysm was approximated as a thin-walled tube and the circumferential stress $\left(\sigma_{\theta}\right)$ was estimated using Laplace's law, i.e. $\sigma_{\theta}=P_{\text {sys }} d o_{\text {sys }} / 2 t$ with $d o_{\text {sys }}$ the outer diameter at systolic pressure $P_{\text {sys }}$ and $t$ the wall thickness. The circumferential force was then obtained as $F_{\theta}=\sigma_{\theta} w h$, with $w$ and $h$ sample width and height respectively. Taking patient M58 as a reference and assuming here that $t=h$ and for $w=6 \mathrm{~mm}$ as marked on Figure 2 $\mathrm{p}$, a physiologically relevant level of $F_{\theta}$ was estimated to be $2.8 \mathrm{~N}$. Assuming an average heart rate of $60 \mathrm{bpm}$, the loading rate can then be averaged out as $F_{\theta}^{\text {sys }}-F_{\theta}^{\text {dias }}[\mathrm{N} / \mathrm{s}], F_{\theta}^{s y s}$ and $F_{\theta}^{\text {dia }}$ being the circumferential force at systole and diastole, respectively. A force-controlled testing protocol was used with a loading rate of $1.2 \mathrm{~N} / \mathrm{s}$. First ten equibiaxial preconditioning cycles up to $1.4 \mathrm{~N}$ were performed. Next, the tissue was stretched up to $2.8 \mathrm{~N}$ in circumferential direction, with five different circumferential to axial force ratios: $0.5: 1,0.75: 1,1: 1$, 1:0.75, 1:0.5. For each ratio, five testing cycles were applied. Forces and images were stored at $30 \mathrm{~Hz}$.

\subsection{Mechanical parameter estimation}

\subsubsection{Empirical parameters}

Three parameters commonly used in literature were used to describe the mechanical properties of arteries through non-invasive assessment. Koullias et al (2005) used the distensibility coefficient ( $D C$, eq. 1) and wall stress ( $W S$, eq. 2) to characterize healthy and aneurysmal ascending aortic tissue, whereas Martin et al (2013b) reported the pressure-strain modulus $\left(P S_{\text {mod }}\right.$, eq. 3) to characterize healthy ascending aorta for different age groups.

$$
D C=\frac{d_{\text {sys }}^{2}-d_{\text {dias }}^{2}}{d_{\text {dias }}^{2}\left(P_{\text {sys }}-P_{\text {dias }}\right)}
$$

$W S=\frac{d_{\text {sys }} P_{\text {sys }}}{2 h_{\text {sys }}}$

$$
P S_{\text {mod }}=\frac{d_{\text {dias }}\left(P_{\text {sys }}-P_{\text {dias }}\right)}{d_{\text {sys }}-d_{\text {dias }}}
$$

In the above equations, $P_{\text {sys }}$ and $P_{\text {dias }}$ are systolic and diastolic blood pressure, respectively. $d_{s y s}$ and $d_{\text {dias }}$ are the outer aortic diameters at systolic and diastolic pressure, and $h_{\text {sys }}$ is the in vivo systolic wall thickness. $D C$ and $P S_{m o d}$ are closely related to each other and reflect the intrinsic stiffness of the vessel. $W S$ is a measure for the amount of pressure applied by the blood on the vessel wall.

\subsubsection{Constitutive parameters}

The above parameters characterize the tissue in a simplified manner, not taking into account the non-linear, anisotropic behaviour of the aorta. Another common way to describe tissue behaviour is through constitutive modelling. The Holzapfel-Gasser-Ogden (HGO) model (eq. 4) is a material model used to represent the behaviour of arterial tissue Gasser et al (2006). It is a structural model which additively decomposes the strain energy density function (SEDF, $\Psi$ ) into an isotropic contribution of the matrix material $\left(\Psi_{m a t}\right)$ and an anisotropic contribution of the two collagen fibre families $\left(\Psi_{c o l}\right)$ :

$$
\begin{aligned}
& \Psi=\Psi_{\text {mat }}+\Psi_{c o l} \\
& \Psi_{\text {mat }}=\frac{\mu}{2}\left(I_{1}-3\right) \\
& \Psi_{c o l}=\frac{k_{1}}{2 k_{2}} \sum_{i=4,6}\left\{\exp \left\{k_{2}\left[\left(\kappa I_{1}+(1-3 \kappa) I_{i}\right)-1\right]^{2}\right\}-1\right\} \\
& I_{1}=\lambda_{r}^{2}+\lambda_{\theta}^{2}+\lambda_{z}^{2}, \quad I_{4,6}=\lambda_{\theta}^{2} \cos ^{2} \alpha+\lambda_{z}^{2} \sin ^{2} \alpha
\end{aligned}
$$

In the strain invariants $I_{1}$ and $I_{4,6}, \lambda_{r}, \lambda_{\theta}$ and $\lambda_{z}$ are the stretches in radial, circumferential, and axial direction, respectively. $\lambda_{\theta}$ and $\lambda_{z}$ are measured during the planar biaxial testing and $\lambda_{r}$ can be calculated from the incompressibility condition $\lambda_{r}=\lambda_{\theta} \lambda_{z}{ }^{-1}$. In the above equations, the shear was considered negligible.

If $k_{2}$ approaches zero, a simplified version of the SEDF is used (Weisbecker et al, 2012):

$\Psi=\frac{\mu}{2}\left(I_{1}-3\right)+\frac{k_{1}}{2} \sum_{i=4,6}\left(I_{i}-1\right)^{2}$.

As for the material model parameters, $\mu$ and $k_{1}$ are stress-like parameters representing the stiffness of the matrix material and the collagen fibres, respectively; $k_{2}$ is a dimensionless parameter which accounts for the nonlinear stiffening of the tissue at higher strains; $\alpha$ is the orientation of the collagen fibre families (defined as an angle w.r.t. the circumferential direction) and $\kappa$ is the dispersion of the collagen fibres about the angle 
$\alpha$. Two symmetrical fibre families are assumed to be embedded in the matrix material.

The above material model parameters are obtained by minimizing the difference between the experimental stresses or pressures and their predictions obtained using the constitutive model. This iterative optimization process was performed in Matlab ${ }^{\circledR}$. The lsqnonlin function and the trust-region-reflective algorithm were used.

Non-invasive estimation In the in vivo case, a cylindrical coordinate system is used. The non-invasively obtained unloading pressure-diameter data and the in vivo wall thickness are used as input to the optimization procedure. The data is fitted using the approach described in (Smoljkić et al, 2015). In short, the minimized objective function included four conditions and is given as:

$$
\begin{aligned}
& \min \left[\sum _ { j = 1 } ^ { n } \left\{\left[w_{p}\left(P_{j}^{\text {mod }}-P_{j}^{\text {exp }}\right)\right]^{2}\right.\right. \\
& \left.+\left[w_{f}\left(\frac{F_{j}^{\text {mod }}}{A_{j}^{\text {mod }}}-\frac{F^{\text {average }}}{A_{j}^{\text {mod }}}\right)\right]^{2}\right\} \\
& +\sum_{k=1}^{m}\left\{\left[w_{\Psi 1}\left(\Psi_{k}^{\text {dias }, \text { mod }}-\Psi^{\text {average }}\right)\right]^{2}\right. \\
& \left.\left.+\left[w_{\Psi 2}\left(\Psi_{k, \text { col }}^{\text {dias } \text { mod }}-\Psi_{k, \text { mat }}^{\text {dias } \text { mod }}\right)\right]^{2}\right\}\right] .
\end{aligned}
$$

The first condition minimizes the difference between the measured pressure $\left(P^{\exp }\right)$ and the model pressure $\left(P^{\mathrm{mod}}\right) . P^{\mathrm{mod}}$ can be calculated by inserting eq. 4 in:

$P_{j}^{\text {mod }}=\int_{\lambda_{\circ}}^{\lambda_{\mathrm{i}}}\left(\lambda_{\theta}^{2} \lambda_{z}-1\right)^{-1} \frac{\partial \Psi}{\partial \lambda_{\theta}} d \lambda_{\theta}$,

where $\lambda_{i}$ and $\lambda_{o}$ are the circumferential stretches at the inner and the outer wall, respectively. Subscript $j$ goes from 1 to $n, n$ being the number of recorded data points.

The second condition ensures that the reduced axial force remains approximately constant in the physiological range. The model prediction of the reduced axial force $\left(F^{\text {mod }}\right.$, the axial force exerted on the aortic tissue without taking the pressure contribution into account) can be calculated with eq. 8.

$$
\begin{aligned}
& F_{j}^{\bmod }=\pi \rho_{\mathrm{i}}^{2}\left(\lambda_{\theta, \mathrm{i}}^{2} \lambda_{z}-1\right) \int_{\lambda_{\mathrm{o}}}^{\lambda_{\mathrm{i}}}\left(\lambda_{\theta}^{2} \lambda_{z}-1\right)^{-2} \\
& \left(2 \lambda_{z} \frac{\partial \Psi}{\partial \lambda_{z}}-\lambda \frac{\partial \Psi}{\partial \lambda_{\theta}}\right) \lambda_{\theta} d \lambda_{\theta}
\end{aligned}
$$

where $\rho_{i}$ stands for the inner radius in the unloaded configuration (i.e. no pressure and no axial prestretch applied). $F^{\text {average }}$ is the result of a zero order polynomial fit with the polyfit function in Matlab ${ }^{\circledR}$, applied on $F^{\text {mod }}$. $A^{\text {mod }}$ is the current cross-sectional area.

The third condition aims to keep the energy across the arterial wall approximately constant at the diastolic pressure. $\Psi^{\text {dias,mod }}$ is the strain energy density at diastolic pressure. To calculate $\Psi^{\text {average }}$ the polyfit function was used on $\Psi^{\text {dias,mod }}$.

The last condition equalizes the collagen energy contribution $\left(\Psi_{\text {col }}^{\text {dias,mod }}\right)$ and the matrix energy contribution ( $\left.\Psi_{\text {mat }}^{\text {dias } m o d}\right)$ at diastole. Subscript $k$ goes from 1 to $m(m=11)$ and represents different points throughout the wall thickness. The weighting factors $w_{p}, w_{f}, w_{\Psi 1}$ and $w_{\Psi 2}$ were set to $1,10^{-2}, 10^{-4}$ and $10^{-1}$, respectively. For a more detailed explanation of the minimized objective function see Smoljkić et al (2015).

When fitting the in vivo data, besides five HGO parameters, additional two geometrical parameters were fitted since they are not measurable in vivo. These two additional parameters are axial prestretch $\left(\lambda_{z}\right)$ and the thickness in the unloaded configuration (H).

Ex situ estimation In the ex situ case, the experimental stresses, stretches in the two directions $\left(\lambda_{\theta}\right.$ and $\lambda_{z}$ ) of the planar biaxial test, and the ex vivo wall thickness were used as an input to a non-linear least squares optimization procedure. The minimized objective function was:

$\min \sum_{j=1}^{n}\left[\left(\sigma_{\theta, j}^{\bmod }-\sigma_{\theta, j}^{e x p}\right)^{2}+\left(\sigma_{z, j}^{\bmod }-\sigma_{z, j}^{e x p}\right)^{2}\right]$,

where, $\boldsymbol{\sigma}^{\text {exp }}$ and $\boldsymbol{\sigma}^{\text {mod }}$ are the experimental and model Cauchy stresses, respectively. $j$ is again the number of data points recorded during a test. The model stresses are calculated from eq. 4 as follows:

$\boldsymbol{\sigma}_{q, j}^{\bmod }=\lambda_{q} \frac{\partial \Psi}{\partial \lambda_{q}}-p, \quad q=\theta, z$

$p$ is the hydrostatic pressure and can be calculated assuming $\boldsymbol{\sigma}_{r}=0$, see Ogden (2009).

The experimental Cauchy stresses are obtained from the first Piola-Kirchhoff stresses through:

$\boldsymbol{\sigma}_{q}^{\exp }=\mathbf{P}_{q}^{\exp } \mathcal{F}^{\mathrm{T}}, \quad q=\theta, z$ 
The deformation gradient $\mathcal{F}$ is equal to $\operatorname{diag}\left(\lambda_{r}, \lambda_{\theta}, \lambda_{z}\right)$. The first Piola-Kirchhoff stresses are in turn calculated from the forces $\mathbf{F}_{q}$ measured during the planar biaxial test and the initial cross-sectional surface area $\mathrm{A}_{q, 0}$ :

$\mathbf{P}_{q}^{\exp }=\frac{\mathbf{F}_{q}}{\mathrm{~A}_{q, 0}}, \quad q=\theta, z$.

$\mathrm{A}_{q, 0}$ is calculated as the length covered by the rakes (6 $\mathrm{mm}$ in our case) multiplied by the initial sample thickness (reported in Table 5). For a more detailed explanation see e.g. Fehervary et al (2016).

\subsubsection{Strength parameters}

In the ex situ setting, strength parameters were obtained from the uniaxial failure tests in both the longitudinal and circumferential direction. Frequently used parameters are the ultimate Cauchy stresses $\left(\sigma^{\text {ult }}\right)$ and ultimate stretches $\left(\lambda^{\text {ult }}\right)$, defined as the stress and stretch values at which the tissue ruptures. $\lambda^{\text {ult }}$ is defined as the current length divided by the initial length. $\sigma^{\text {ult }}$ was calculated as the applied load (F) divided by the current cross-sectional area, which comes to $\sigma^{\text {ult }}=\mathrm{F} \quad \lambda^{\text {ult }} / \mathrm{A}_{0}$ if incompressibility is assumed. $\mathrm{A}_{0}$ is the initial cross-sectional area.

In the in vivo setting, the circumferential physiological stress and stretch range were estimated. The circumferential stress $\left(\sigma_{\theta}^{\text {phys }}\right)$ was calculated at diastolic and systolic pressure assuming the aorta to be a thin-walled tube (Laplace law). The circumferential stretch $\left(\lambda_{\theta}^{\text {phys }}\right)$ was calculated as the in vivo circumference of the aorta at diastolic and systolic pressure divided by the ex vivo circumference in the unloaded configuration.

Combining the above, the relative distance between $\sigma_{\theta}^{\text {ult }}$ and $\sigma_{\theta}^{\text {phys }}$ on the one hand and between $\lambda_{\theta}^{\text {ult }}$ to $\lambda_{\theta}^{\text {phys }}$ on the other, serve as rupture risk indicators.

\section{Results}

\subsection{Data acquisition}

\subsubsection{Pre-operative pressure-diameter curves}

The in vivo pressure-diameter curves of all six patients are shown on Figure 3. It is nicely apparent from this figure that only patient F74 has diameter values over $55 \mathrm{~mm}$.
Table 2 The wall thickness of the entire dataset. The in vivo thickness was measured via epiaortic echocardiography at systolic and diastolic blood pressure (sys - dias). Ex vivo measurments were performed through histology and with a thickness-measuring device. IMT and IMAT are the intima-media thickness and intima-media-adventitia thickness, respectively. Avg. stands for average and SD for standard deviation. All measurements are reported in millimetres.

\begin{tabular}{lccc}
\hline Method & $\begin{array}{c}\text { Epiaotic echo } \\
\text { (sys-dias) }\end{array}$ & $\begin{array}{c}\text { Histology } \\
(\text { Avg. } \pm \text { SD) }\end{array}$ & $\begin{array}{c}\text { Thickness device } \\
\text { (Avg. } \pm \text { SD })\end{array}$ \\
\hline Type & In vivo & Ex situ & Ex situ \\
& IMT & IMT & IMAT \\
\hline F74 & $1.5-2.0$ & $2.00 \pm 0.28$ & $3.5 \pm 0.7$ \\
F68 & $1.0-1.2$ & $1.33 \pm 0.29$ & $2.5 \pm 0.3$ \\
M58 & $1.0-1.1$ & $1.33 \pm 0.22$ & $2.6 \pm 0.3$ \\
M60 & $1.3-1.5$ & $1.32 \pm 0.28$ & $2.7 \pm 0.4$ \\
M52 & $1.1-1.4$ & $1.42 \pm 0.26$ & $2.2 \pm 0.2$ \\
M55 & $1.4-1.8$ & $1.25 \pm 0.10$ & $2.8 \pm 0.4$ \\
\hline
\end{tabular}

\subsubsection{Thickness measurements}

The aortic wall thickness was measured both in vivo using an epiaortic ultrasound probe (IMT) and ex situ through histology (IMT) as well as prior to the mechanical experiments (IMAT). The thickness values obtained with each of these measuring techniques are reported in Table 2 .

\subsubsection{Mechanical testing}

The samples of five out of six patients were successfully tested mechanically. The stress-stretch curves of these patients obtained from the planar biaxial tests are shown on Figure 4 . Multiple samples per patient are tested and plotted. The circumferential stress-stretch curves obtained from uniaxial testing are shown in Figure 5 .

Note however that all uniaxial curves show a slight underestimation of the stretch, since the displacement of the clamps was used for the calculation of the stretch although the samples were dogbone-shaped.

\subsection{Mechanical parameter estimation}

\subsubsection{Empirical parameters}

The empirical parameters calculated for the six patients are presented in Table 3, along with a literature overview of the same parameters for normal and aneurysmal tissue. Koullias et al (2005) previously calculated the $D C$ and the $W S$ of human (aneurysmal) ascending aortas for a group of 53 patients. The investigated group was split in normal and aneurysmal (aortic diameter $>50 \mathrm{~mm}$ ) aortas and 


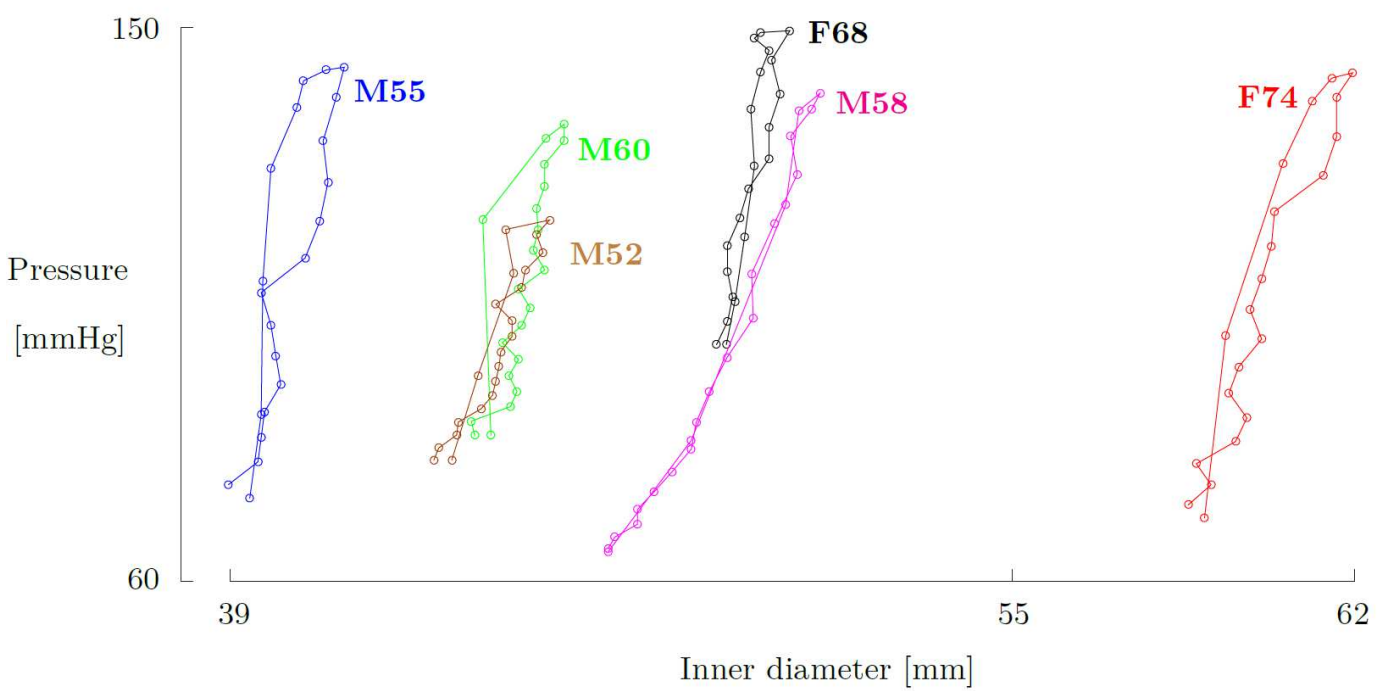

Fig. 3 Non-invasively obtained pressure-diameter curves of all six patients.
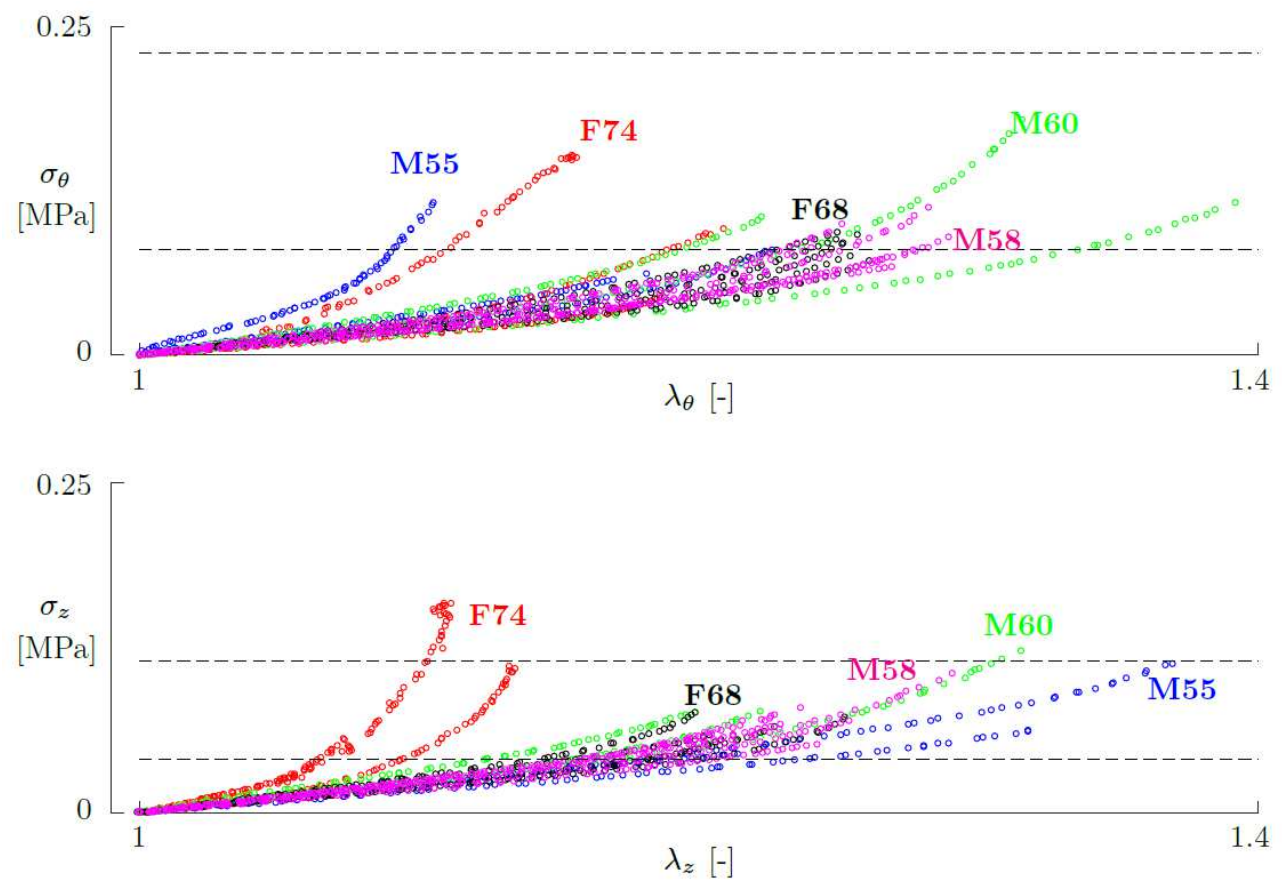

Fig. 4 Biaxially obtained stress-stretch curves for the five tested patients (multiple samples per patient). The data is plotted for the circumferential and axial direction and for 1:0.75 ratio. The dashed lines represent the physiological stress range. The circumferential stress was estimated with Laplace's Law and the axial was calculated to be half of the circumferential. The lower line is the lowest diastolic stress from all patients and the upper one is the highest systolic stress from all patients.

for both parameters the average and standard deviation were calculated. Okamoto et al (2003) similarly computed the $D C$ for 7 ATAA patients. Martin et al (2013b) calculated the $P S_{\text {mod }}$ for 45 male patients for different age categories $(30-49,50-59$, $60-79)$.

\subsubsection{Constitutive parameters}

Non-invasive estimation The non-invasive estimation of the HGO parameters revealed a good fit between the modelled and the experimental values. The average coefficient of determination $\left(\mathrm{R}^{2}\right)$ was $0.90 \pm$ 0.07 . The parameters obtained from the in vivo data are reported in Table 4 Figure 6 shows an example of 

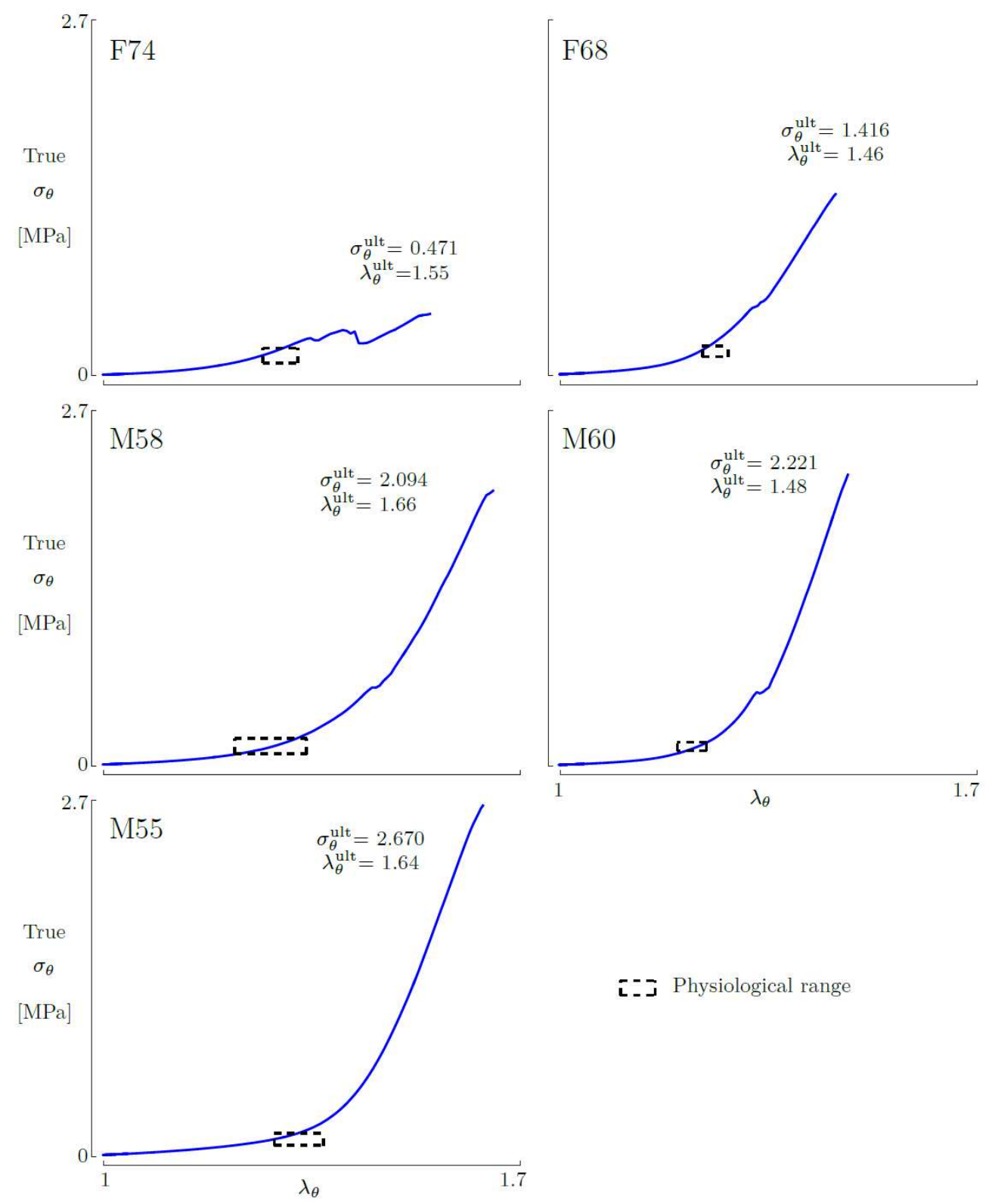

こ:こ Physiological range

Fig. 5 Uniaxial circumferential stress-stretch curves for the five tested patients. The ultimate Cauchy stress and ultimate stretch are reported on each graph.

the non-invasive fit for one patient with all four minimized conditions explained in the 2.2 section.

Ex situ estimation The HGO parameters from all samples and all patients tested in planar biaxial mode are reported in Table 5 The invasive estimation of the HGO parameters resulted in good fits between the modelled and the experimental values. The average $\mathrm{R}^{2}$ was $0.97 \pm 0.02$. Figure 7 shows an example of the experimental stress-stretch curves and the model fit for patient M60.

\subsubsection{Strength parameters}

Ultimate stress and stretch in circumferential and longitudinal direction were obtained from the uniaxial stress-stretch curves (see Figure 5). The results are presented in Table 6] and compared with literature. García-Herrera et al (2012) calculated the ultimate stress and stretch for normal and aneurysmal aortic tissue. The control group (with subjects older than 35 ) consisted of 12 patients and had an average diameter of $23.7 \pm 4.4 \mathrm{~mm}$. The aneurysm group consisted of 11 patients and had an average diameter of $38.5 \pm 7.7 \mathrm{~mm}$. The aneurysmal group with BAV 
Table 3 The empirical and strength parameters of the six patients examined in this study. Avg. and SD stand for average and standard deviations, respectively. The results reported in literature for healthy and aneurysmal tissue are listed at the bottom of the table. The patients are ordered on decreasing aortic size. In some cases, DC is calculated differently than in this study. Please, check the references to see the original equations.

\begin{tabular}{|c|c|c|c|c|c|c|}
\hline Patient & \multicolumn{2}{|l|}{$\begin{array}{c}\mathrm{DC} \\
{\left[10^{-3} \mathrm{mmHg}^{-1}\right]}\end{array}$} & \multicolumn{3}{|c|}{$\begin{array}{c}\mathrm{WS} \\
{[\mathrm{kPa}]}\end{array}$} & $\begin{array}{c}\mathrm{PS}_{\mathrm{mod}} \\
{[\mathrm{kPa}]}\end{array}$ \\
\hline F74 & \multicolumn{2}{|l|}{1.74} & \multicolumn{3}{|c|}{402} & 158 \\
\hline F68 & \multirow{2}{*}{\multicolumn{2}{|c|}{$\begin{array}{l}1.37 \\
2.93\end{array}$}} & \multicolumn{3}{|c|}{522} & 197 \\
\hline M58 & & & \multirow{2}{*}{\multicolumn{3}{|c|}{$\begin{array}{l}447 \\
309\end{array}$}} & 95 \\
\hline M60 & \multicolumn{2}{|l|}{1.20} & & & & 227 \\
\hline M52 & \multicolumn{2}{|l|}{3.00} & \multicolumn{3}{|c|}{303} & 91 \\
\hline M55 & \multicolumn{2}{|l|}{1.87} & \multicolumn{3}{|c|}{284} & 147 \\
\hline Avg. & \multirow{2}{*}{\multicolumn{2}{|c|}{$\begin{array}{l}2.02 \\
0.77 \\
\end{array}$}} & \multirow{2}{*}{\multicolumn{3}{|c|}{$\begin{array}{c}378 \\
95 \\
\end{array}$}} & 153 \\
\hline SD & & & & & & 54 \\
\hline Healthy & $2.50 \pm 0.49$ Koullias et al & 2005 & $93 \pm 6$ & Koullias et al & 2005 & 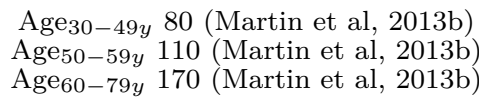 \\
\hline Aneurysm & $\begin{array}{r}>5 \mathrm{~cm} 1.45 \pm 0.38 \text { (Koullias e } \\
1.46 \pm 0.83 \text { (Okamoto et al }\end{array}$ & \begin{tabular}{l|l|}
$\mathrm{t}$ al & 2005 \\
2003
\end{tabular} & $245 \pm 63$ & Koullias et al & 2005 & - \\
\hline
\end{tabular}

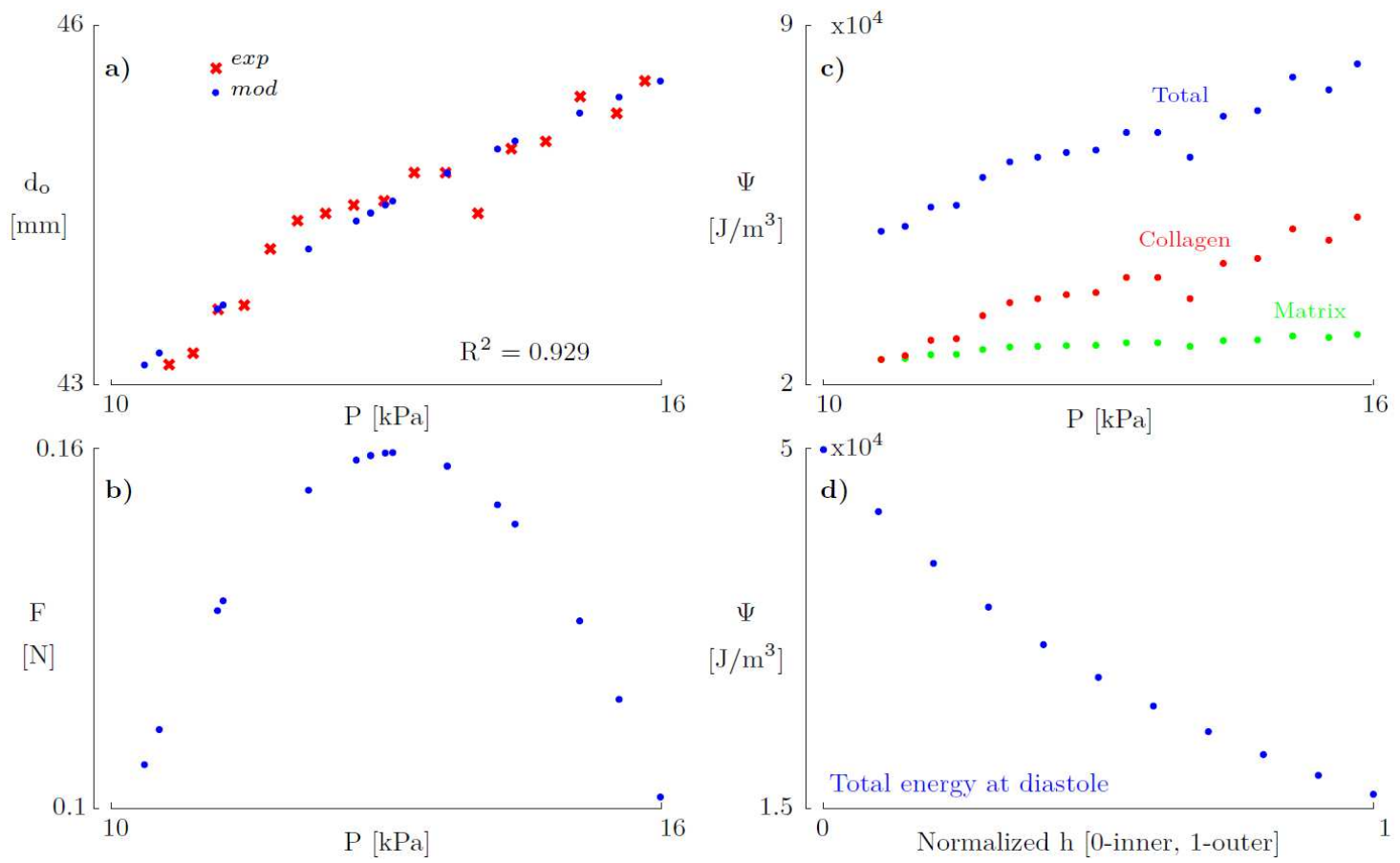

Fig. 6 Results of the non-invasive fit for patient M52. The four minimized conditions are plotted in the following order: a) The in vivo measured pressure $(\mathrm{P})$ and the outer diameter $\left(\mathrm{d}_{\mathrm{i}}\right)$ data (red $\mathrm{x}$ ) and the HGO model fit (blue dots); b) Reduced axial force $(\mathrm{F})$ predicted by the HGO model; c) Strain energy density $(\Psi)$ - total and split into collagen and matrix contribution; d) $\Psi$ throughout the aortic wall thickness $(\mathrm{h})$ - from inner to outer wall.

consisted of 11 patients and had an average diameter of $38.0 \pm 2.0 \mathrm{~mm}$. Vorp et al (2003) uniaxially tested 54 test-specimens (40 ATAA and 14 control) and calculate the ultimate stress for these groups. (Iliopoulos et al, 2009) tested 26 aneurysmal patients and 15 non-aneurysmal patients and calculated the ultimate stress and stretch. Sommer et al (2016) preformed uniaxial tests on 7 circumferential, 10 axial and 13 radial aneurysmal samples. The results of the four research groups are shown at the bottom of Table 6 for comparison.
Table 6 also reports the ratios of the estimated physiological stress or stretch (at systole) and the ultimate stress or stretch, for our data set. This was also visualized on Figure 5 where the physiological stress and stretch range for each patient is marked. Comparing this range to the patient-specific ultimate stress and stretch provides an indication of rupture risk. 
Table 4 The seven non-invasively obtained HGO model parameters. The coefficient of determination $\left(\mathrm{R}^{2}\right)$ indicates the quality of the fit.

\begin{tabular}{|c|c|c|c|c|c|c|c|}
\hline \multicolumn{2}{|c|}{ Patient } & \multirow{2}{*}{$\begin{array}{l}\text { F74* } \\
190.2\end{array}$} & \multirow{2}{*}{$\begin{array}{l}\text { F68* } \\
306.7\end{array}$} & \multirow{2}{*}{$\begin{array}{l}\text { M58 } \\
98.2\end{array}$} & \multirow{2}{*}{$\begin{array}{c}\text { M60 } \\
6.2\end{array}$} & \multirow{2}{*}{$\begin{array}{c}\text { M52 } \\
3.6\end{array}$} & \multirow{2}{*}{$\begin{array}{c}\text { M55 } \\
119.4\end{array}$} \\
\hline$\mu$ & {$[\mathrm{kPa}]$} & & & & & & \\
\hline$k_{1}$ & {$[\mathrm{kPa}]$} & 466.5 & 756.4 & 16.5 & 3.4 & 5.1 & 36.3 \\
\hline$k_{2}$ & {$[/]$} & - & - & 0.63 & 3.56 & 1.59 & 11.38 \\
\hline$\alpha$ & [deg] & 40.6 & 40.0 & 36.9 & 31.5 & 82.1 & 58.9 \\
\hline$\kappa$ & {$[/]$} & 0 & 0 & 0.012 & 0.004 & 0.030 & 0.243 \\
\hline$H$ & {$[\mathrm{~mm}]$} & 2.11 & 1.28 & 3.11 & 2.95 & 5.00 & 2.82 \\
\hline$\lambda_{z}$ & {$[/]$} & 1.02 & 1.02 & 1.78 & 1.59 & 1.00 & 1.06 \\
\hline \multicolumn{2}{|c|}{$\mathrm{R}^{2}$} & 0.93 & 0.92 & 0.99 & 0.86 & 0.93 & 0.90 \\
\hline
\end{tabular}

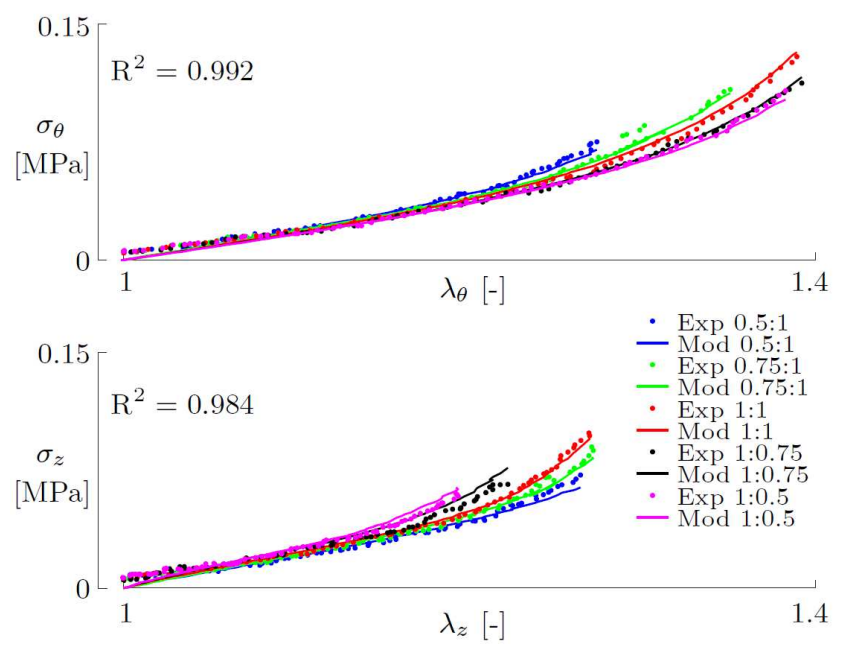

Fig. 7 Experimental stress-stretch curves (dotted lines) and HGO model fits (full lines) for M60-S2. All tested ratios (circumferential:axial) are plotted.

\section{Discussion}

This study provides detailed clinical and mechanical data on six ATAA patients who underwent elective surgery repair. An in depth analysis is performed on parameters that can be obtained in vivo and those that can only be obtained ex situ. An overall limitation of the study is the number of patients $(n=6)$, and the diversity of the patient group (i.e. only one patient, F74, was admitted to surgery according to the 'normal' procedure, i.e. without confounding factors such as BAV). To reach a more general conclusion, the study should be repeated on a larger number of specimens. Nevertheless, the degree of detail of the obtained information of each of the patients is unprecedented and therefore considered highly valuable to the study of ATAA. Below, the obtained results are discussed in detail, indicating possible study limitations and, where possible, relating the results to literature.

\subsection{Data acquisition}

\subsubsection{Pre-operative pressure-diameter curves}

The non-invasively obtained pressure diameter curves shown on Figure 3 provide immediate insight into a number of important parameters such as minimum and maximum diameter and pressure, degree of hysteresis and slope, and therefore by themselves already serve as a useful visual inspection tool for the physician. Time-resolved CT scans are required to obtain these curves, which is relatively easy to fit into the clinical workflow since patients in follow-up for ATAA are regularly scheduled for a CT scan anyway, but implies a slightly higher radiation dose. Though more data points would undoubtedly be useful, the trade-off between radiation dose and number of points in the cardiac cycle yielded a maximum of 21 data points on the pressure-diameter graph. Note that an important benefit of having images throughout the cardiac cycle is that the maximal diameter of the aneurysm can be measured more precisely than with a standard, non-gated single CT scan.

\subsubsection{Thickness measurements}

Table 2 exposes the largest wall thickness in patient F74, which was also the patient with the largest ATAA diameter and the weakest mechanical properties. The higher thickness can be explained by the thickening of the intimal layer, commonly seen in diseased aortic tissue. The same table also exposes a large variability in thickness due to the measurement method. The average ex vivo wall thickness measured with the device is remarkably higher than the average ex vivo wall thickness measured from the histological slices (Table 2). This can be explained by the fact that the histological measurements exclude the adventitia from the measurement. In general, the in vivo wall thickness is lowest, as can be expected since radial contraction is induced by the Poisson effect when the tissue is loaded. For patients M60 and M55 however, the ex vivo wall thickness (in unloaded state) is slightly smaller than the in vivo wall thickness (in loaded state). This non-intuitive result can be explained by the fact that the thickness obtained from histology is an averaged value along the wall of the sample, which shows high variation. The echo on the other hand, measures only a small portion of the aortic wall, which in this case coincided with a region of lower thickness.

It is important to note that no reliable non-invasive method is currently available for aortic 
Table 5 Results of the invasive constitutive modelling, based on the planar biaxial tests. Besides HGO parameters, sample thickness H, measured with the device on Figure 1 , is reported.

\begin{tabular}{lccccccc}
\hline Patient-Sample & $\mathrm{H}[\mathrm{mm}]$ & $\mu[\mathrm{kPa}]$ & $k_{1}[\mathrm{kPa}]$ & $k_{2}[-]$ & $\alpha[\mathrm{deg}]$ & $\kappa[-]$ & $\mathrm{R}^{2}$ \\
\hline F74-S1 & 2,75 & 32,1 & 2035,9 & 14,16 & 90 & 0,33 & 0,93 \\
F74-S2 & 3,25 & 21,9 & 477,6 & 20,19 & 90 & 0,31 & 0,96 \\
F74-S5 & 4,80 & 33,3 & 38,2 & 100.00 & 67.2 & 0,18 & 0,91 \\
\hline F68-S1 & 2,23 & 44,7 & 62,3 & 40,51 & 0 & 0,329 & 0,97 \\
F68-S2 & 2,63 & 33,6 & 25,5 & 39,53 & 0 & 0,316 & 0,98 \\
F68-S3 & 2,65 & 38,5 & 7,8 & 18,56 & 27.5 & 0,206 & 0,98 \\
F68-S4 & 2,7 & 34,6 & 28,5 & 37,93 & 23.5 & 0,326 & 0,97 \\
F68-S5 & 2,8 & 41,3 & 43,1 & 5,87 & 28.6 & 0,241 & 0,98 \\
\hline M58-S1 & 2,44 & 42,3 & 59,9 & 14,06 & 0 & 0,296 & 0,98 \\
M58-S2 & 2,91 & 33,0 & 62,5 & 7,11 & 0 & 0,314 & 0,99 \\
M58-S3 & 2,41 & 40,1 & 55,7 & 14,86 & 0 & 0,320 & 0,99 \\
M58-S4 & 2,82 & 35,4 & 63,5 & 13,16 & 0 & 0,316 & 0,98 \\
M58-S5 & 3,15 & 29,1 & 50,8 & 1,73 & 0 & 0,284 & 0,97 \\
M58-S6 & 2,42 & 42,4 & 53,2 & 10,54 & 0 & 0,294 & 0,98 \\
\hline M60-S2 & 2,50 & 40,0 & 45,8 & 8,34 & 0 & 0,273 & 0,97 \\
M60-S4 & 3,30 & 55.2 & 57,0 & 15,53 & 0 & 0,270 & 0,99 \\
M60-S5 & 3,32 & 34,5 & 43,5 & 7,91 & 0 & 0,316 & 0,99 \\
\hline M55-S1 & 3,40 & 33,1 & 18,2 & 10,11 & 0 & 0,222 & 0,98 \\
M55-S2 & 2,95 & 43,6 & 6,3 & 3,35 & 14.9 & 0 & 0,96 \\
M55-S3 & 3,10 & 47,2 & 28,9 & 12,64 & 27.5 & 0,108 & 0,96 \\
\hline
\end{tabular}

Table 6 The strength parameters of all successfully tested uniaxial samples. Reported stress is Cauchy stress. Avg and SD stand for the average values and standard deviations, respectively. The results reported in literature for healthy and aneurysmal tissue are listed at the bottom of the table. Note that García-Herrera et al (2012) and Iliopoulos et al (2009) report rupture stresses as being the maximum stress before the specimen's first rupture. In García-Herrera et al (2012), this rupture stress is reported to be $<5 \%$ lower than the ultimate stress. The numbers in brackets stand for different references, as follows: (1) - Vorp et al (2003), (2) - García-Herrera et al (2012), (3) - Iliopoulos et al (2009), (4) - Sommer et al (2016).

\begin{tabular}{|c|c|c|c|c|c|c|c|}
\hline Sample & $\sigma_{\theta}^{\mathrm{ult}}[\mathrm{MPa}]$ & $\lambda_{\theta}^{\mathrm{ult}}[-]$ & $\sigma_{\theta}^{\text {physio }} / \sigma_{\theta}^{u l t}$ & $\lambda_{\theta}^{\text {physio }} / \lambda_{\theta}^{u l t}$ & Sample & $\sigma_{z}^{\mathrm{ult}}[\mathrm{MPa}]$ & $\lambda_{z}^{\mathrm{ult}}[-]$ \\
\hline Healthy & $\begin{array}{c}1.80 \pm 0.24(1) \\
1.20 \pm 0.20(2) \\
1.60^{* *}(3)\end{array}$ & $\begin{array}{l}1.8^{* *}(2) \\
1.6^{* *}(3)\end{array}$ & - & - & - & $\begin{array}{c}1.71 \pm 0.14(1) \\
0.66 \pm 0.07(2) \\
0.88^{* *}(3)\end{array}$ & $\begin{array}{l}1.8^{* *}(2) \\
1.6^{* *}(3)\end{array}$ \\
\hline Aneurysm & $\begin{array}{c}1.18 \pm 0.12(1) \\
1.19 \pm 0.13(2) \\
1.23 \pm 0.15^{*}(2) \\
1.62^{* *}(3) \\
1.28 \pm 0.82(4)\end{array}$ & $\begin{array}{c}1.75^{* *}(2) \\
1.8^{*, * *}(2) \\
1.55^{* *}(3) \\
1.52 \pm 0.20(4)\end{array}$ & - & - & - & $\begin{array}{c}1.21 \pm 0.09(1) \\
0.88 \pm 0.10(2) \\
0.84 \pm 0.10^{*}(2) \\
1.20^{* *}(3) \\
0.57 \pm 0.20\end{array}$ & $\begin{array}{c}1.75^{* *}(2) \\
\approx 1.58^{*}(2) \\
1.52^{* *}(3) \\
1.50 \pm 0.18(4)\end{array}$ \\
\hline
\end{tabular}

wall thickness measurement. At this point, the most promising technique is magnetic resonance imaging (MRI). However, even with a state-of-the-art 7T MRI, the resolution of the obtained measurement is only around $0.5 \mathrm{~m}$ (Sinnecker et al, 2012). The tissue itself also has a varying thickness. However, current measuring techniques do not provide satisfying resolution and image quality to obtain an in vivo map of local wall thicknesses.

\subsubsection{Mechanical testing}

Ex situ mechanical tests were performed on samples of all six patients. For five out of six this yielded reliable data. Note how the results of the mechanical tests performed ex situ should be interpreted with care, since the samples were frozen at $-80^{\circ} \mathrm{C}$ and slowly defrosted prior to testing. Studies that investigated the effect of freezing at $-20^{\circ} \mathrm{C}$ and $-80^{\circ} \mathrm{C}$ report 
contradictory results. Stemper et al 2007) report no effect of freezing on porcine aortas. Venkatasubramanian et al (2006) report an effect of freezing on the mechanical response in the low-strain region for porcine femoral arteries. Finally, Chow and Zhang (2011) report no effect in low-strain region but increase in the stiff region for bovine thoracic aortas.

\subsection{Mechanical parameter estimation}

\subsubsection{Empirical parameters}

The distensibility coefficient (DC) is a measure of the stiffness of the aorta. It is associated with the capacity of the vessel to dilate during pressure changes. ATAA tissue is expected to be stiffer than healthy ascending aortic tissue and thus, to be less capable of withstanding big pressure differences. These expectations are reflected in the results reported by Koullias et al (2005). ATAA tissue has lower distensibility values than healthy tissue. Based on DC, the dataset of our six patients can be divided into two groups. Patients M58 and M52 have DC in the range of the healthy tissue $\left(2.50 \pm 0.49 \mathrm{mmHg}^{-1}\right)$, while patients F74, F68, M60 and M55 have DC in the range of aneurysmal tissue $\left(1.45 \pm 0.38 \mathrm{mmHg}^{-1}\right)$. The latter samples are thus stiffer. Okamoto et al (2003) report a similar value for aneurysm distensibility $\left(1.46 \pm 0.83 \mathrm{mmHg}^{-1}\right)$, confirming the results reported by Koullias et al (2005).

Another measure of aortic stiffness is the pressure-strain modulus $\left(P S_{m o d}\right)$. This coefficient is similar to the reciprocal of the DC, except that the pressure range becomes more important relative to the diameter range for the $P S_{\text {mod }}$ as the difference between diastolic and systolic diameter is not squared in the latter. To our knowledge, no $P S_{m o d}$-values for ATAA tissue are reported in literature, but Martin et al (2013b) computed the $P S_{\text {mod }}$ for healthy ascending aortic tissue from different age groups (see Table 66. The results reveal that the aorta stiffens with age. Compared to their respective age-categories, patients F74, M58 and M52 have normal $P S_{\text {mod }}$ whereas patients F68, M60 and M55 show $P S_{\text {mod }}$ far above their respective categories. Given the fact that the $P S_{\text {mod }}$ is similar to the $D C$ and that both aneurysm development and ageing stiffen the aortic tissue, it may not surprise that the outliers of the $D C$ correspond to those of the $P S_{\text {mod }}$. According to Martin et al (2013a), $P S_{m o d}$ may be a more reliable indicator of rupture potential than the maximal diameter criterion. They report that patients with $P S_{\text {mod }}$-values higher than $100 \mathrm{kPa}$ are at higher risk of rupture. Four out of six patients from our dataset had values higher than 100. However, based on the performed uniaxial failure tests the higher risk classification was only confirmed for patient F74.

The wall stress $(W S)$ is defined as the amount of pressure applied by the blood on the vessel wall. WS reported in literature by Koullias et al (2005) are presented in table 3 and reveal that ATAA tissue has an increased $W S$ compared to healthy tissue $(245 \pm 63$ $\mathrm{kPa}$ vs. $93 \pm 6 \mathrm{kPa}$ ). From our dataset, three patients have a $W S$ that is in the range of the aneurysmal wall stresses as depicted by Koullias et al (2005) (patients M60, M52 and M55). The other three patients (F74, F68, M58) have wall stresses far above this range. A possible explanation for the high difference in $W S$ between our dataset and the values reported in Koullias et al (2005) is the wall thickness that is used for the calculations. Koullias et al (2005) report systolic wall thicknesses of healthy aortas of $2.28 \pm 0.20$ $\mathrm{mm}$ and for aneurysmal tissue of $2.45 \pm 0.19 \mathrm{~mm}$, whereas for our dataset all in vivo measured wall thicknesses are smaller than $2 \mathrm{~mm}$ (see Table 2). The $W S$-values are, regardless of one exception (patient F74), positively related to the diameter size of the patients. However, when examining the $W S$-values of all patients, patient F74 does not stand out, even though this patient's tissue strength was clearly reduced compared to the others. However, patient F74 also had a very thick aortic wall compared to the other samples, which explains the lower $W S$-value. This confirms the limited reliability of $W S$ as a rupture risk indicator, due to its high sensitivity to the wall thickness measurement.

\subsubsection{Constitutive parameters}

Non-invasive estimation The HGO parameters for each patient, resulting from the non-invasive parameter estimation approach, are reported in Table 4. These parameters are, however, difficult to interpret and vary between patients. Compared to the invasively obtained HGO parameters reported in Table 5. it can be noticed that in vivo $\mu$ values are an order of magnitude higher. $k_{1}$ is sometimes higher ex vivo and sometimes in situ, while $k_{2}$ values are either similar or higher in the in situ case. The collagen fibre angle $\alpha$ was on average 26.9 degrees but with an almost equally big standard deviation $(21,4)$ as an indicator of a big patient variability. $\kappa$ was lower than invasively obtained.

When using in vivo data for the non-invasive estimation of the constitutive parameters, assumptions related to the reduced axial force and the 
SED (explained in subsection 2.2.2 were used. These assumptions were derived from literature or based on our own experimental data (see Smoljkić et al (2015) for more detail) and are developed for healthy tissues. It might be the case that these assumptions do not hold for aneurysmal tissue, which is something that requires further investigation. Additionally, the aneurysm is in this case assumed to be a perfect cylinder which is far from reality. Experimental findings show that in a region of aneurysmal changes wall properties can vary drastically even between very close sections (Niestrawska et al, 2016). However, taking a full geometry into account for in vivo parameter estimation makes the process more complex, time consuming and therefore less feasible to incorporate into a clinical work-flow.

Note also that, in the non-invasive parameter estimation, we consider the unloaded configuration to be the stress-free configuration, consequently neglecting the residual circumferential stresses. Since an in vivo measurement of these residual stresses is not possible it would have to be implemented as an additional fitting parameter. Since there are already seven parameters that are fitted in the non-invasive estimation procedure, we decided to not include the opening angle as one of them.

Ex situ estimation To our knowledge, no HGO parameters from planar biaxial tests have previously been reported for ATAAs. Azadani et al (2013) and Martin et al (2013a) preformed planar biaxial tests and fitted Fung-type SEDF to the experimental curves. The invasively obtained HGO parameters presented in Table 5 can however be compared to the results from uniaxial tests on ATAA performed in Pierce et al (2015) and Pasta et al (2015). Pierce et al (2015) fitted HGO parameters and additional damage parameters to the data. Pasta et al (2015) fitted the HGO model to layer-specific uniaxial data and to the uniaxial data combined with image-based fibre analysis (in the latter only $\mu, k_{1}$ and $k_{2}$ were fitted). Parameter values for $\mu$ reported in the present study were in the same range as in Pierce et al (2015) (0.022-0.046 $\mathrm{MPa}$ in our case and 0.018-0.046 $\mathrm{MPa}$ in Pierce et al (2015)). (Pasta et al, 2015) tested two separated layers and report average parameters for each layer for two aneurysmal tissue groups (based on the geometry of the aortic valve, i. e. bicuspid or tricuspid). $\mu$ values reported there are lower, between 4.5 and $5.9 \mathrm{kPa}$ in the case when all five material parameters were fitted.

When comparing $k_{1}$ values, our results, ranging from 0.006 to $2.036 \mathrm{MPa}$, are comparable both to
Pierce et al (2015), which reports values from 0.12 to 9.07 MPa and to Pasta et al (2015) with average values between 0.112 and $0.177 \mathrm{MPa}$. Comparable values were obtained for $k_{2}$ as well (1.73-100 our results, 0-94.63 in Pierce et al (2015) and 7.4-8.5 in Pasta et al (2015)).

Parameter $\alpha$ often went to its lower limit. From a microscopic point of view this means that the fibre bundles are aligned in the circumferential direction of the vessel wall. This is in accordance with findings reported in Haskett et al (2010) for healthy ascending aorta. However, the aneurysms were modelled as a one-layered structure and the same paper reports that the physiological meaning of $\alpha$ disappears when the three layers of the arterial wall are modelled together.

The dispersion-related parameter $\kappa$ has a median value of 0.295 which is higher than 0.039 - the median value reported in Pierce et al (2015). Pasta et al (2015) reports average fitted values for different layers between 0.17 and 0.29 , while the values obtained from multiphoton imaging range between 0.22 and 0.27 .

It is important to consider that the HGO model used in this study is originally developed for healthy arterial tissue. Additionally, it takes into account only the passive response of the tissue, which is correct for the ex situ data, but not for the in vivo case where the active contribution of the smooth muscle cells plays a role as well. To investigate the effect of SMCs, an additional FE simulation would be required which would, besides the passive behavior, include the active contribution of SMCs. By fitting the HGO model to the pressure-force data provided by that simulation, the relevance of the active contribution could be quantified. Also, in the case of ATAA tissue, the regional heterogeneity might be important, which is something that was not accounted for in this study. All these factors might explain the fact that the HGO parameters obtained in this study do not manage to distinguish between patients, or to expose patients at risk.

\subsubsection{Strength parameters}

In Table 6, patient F74 clearly stands out from the others by its low ultimate stress and by the fact that the estimated physiological stress-stretch region is located very close to the rupture point 5 This patient was also the only one with a diameter above $55 \mathrm{~mm}$. All these elements point towards a higher rupture risk for this patient compared to the others. Table 6 also illustrates that, except for patient F74, the ultimate circumferential strength is higher or similar to the ultimate axial strength of the tissue $(1.44 \pm 0.75 \mathrm{MPa}$ 
vs. $0.91 \pm 0.15 \mathrm{MPa}$ ). These results are confirmed by several studies (Iliopoulos et al, 2009, García-Herrera et al, 2012, Koullias et al, 2005, Sommer et al, 2016, Khanafer et al, 2011). In contrast, in Vorp et al (2003) no directional strength differences were noticed. Similarly, there is no agreement in literature on whether or not the ultimate strength is significantly lower for aneurysmal tissue than for healthy tissue. In García-Herrera et al (2012) and Vorp et al (2003) a difference was reported, while in Iliopoulos et al (2009) no difference was noticed.

The directional differences in ultimate stretches are minor in our dataset $(1.57 \pm 0.10 \mathrm{MPa}$ (circ) vs. $1.56 \pm 0.06 \mathrm{MPa}$ (axial)). This trend is confirmed by literature. No differences in ultimate stretches between aneurysm and healthy tissue are noticed in García-Herrera et al (2012); Iliopoulos et al (2009); Vorp et al (2003); Sommer et al (2016). An interesting analysis of the difference between the axial and circumferential direction in ATAAs was done by Duprey et al (2010). In their study, the tissue's elastic modulus was significantly higher in the circumferential than in the axial direction and they attribute the presence of the anisotropy to the mechanical requirements of the tissue.

The large spread in ultimate circumferential stress indicates a strong patient specificity of the rupture risk. Secondly, there was no correlation between the ultimate circumferential stress and the patient's diameter. A more indicative predictor is the ratio of the in vivo wall stress to ultimate circumferential stress (both are reported in Table 6 for each patient). However, the latter can obviously not be measured pre-operatively whereas the former is highly sensitive to the measured wall thickness and should be calculated more accurately than by using thin-walled tube theory. Though research groups have already identified the need for more accurate calculation of wall stress through finite element simulations on a patient-specific geometry, this study also indicates the strong need for reliable estimation of patient-specific ultimate stress, by identifying correlations with parameters that can be acquired pre-operatively.

Duprey et al (2016) calculated the rupture risk of ATAA tissue of 31 patients based on both stress and stretch. They concluded that the ratio of the in vivo stress and the strength is in general low. Instead, a ratio based on the in vivo and ultimate stretch should be considered and can be even more physiologically meaningful. Table 6 reports the ratios of the estimated physiological stress or stretch (at systole) and the ultimate stress or stretch, for our data set. The stress ratio was indeed lower than the stretch ratio. The stretch-based values had similar values among patients (0.77 - 0.88) while the stress-based values had a bigger spread $(0.07-0.45)$. The stress-based rupture risk was able to better indicate the patient who was at higher risk of rupture, i.e. F74. However, since the stretch-based rupture risk results in similar values for all patients, it would be possible to estimate the patient-specific ultimate stretch, under the assumption that the physiological stretch is known.

\section{Conclusion}

There is a growing consensus that diameter information alone does not suffice for rupture risk estimation of ATAA and that mechanical parameters should be included in the risk assessment. However, our knowledge on the mechanical properties of ascending thoracic tissues, both healthy and aneurysmal, is still scarce. This study provides information on the geometrical and mechanical properties of the ATAA of 6 patients with unprecedented detail. To the best of authors' knowledge, the HGO material parameters of ATAA tissue based on planar biaxial testing have not been previously reported. They are, however, essential to the development of reliable FE models. Due to the fact that the in vivo conditions used for the parameter identification were only evaluated for healthy tissue, we advise to use the parameters obtained ex vivo.

From this study, it is confirmed that either mechanical or geometrical information alone cannot provide sufficient information regarding rupture risk. Rather, the ratio of phsyiological wall stress to ultimate wall stress seems to be the most convincing parameter. Nevertheless, the accurate and non-invasive estimation of both factors in this ratio is highly challenging. Physiological wall stress can be estimated using relatively simple, empirical methods, or more complex, FE-based methods. Either way, the estimation suffers from uncertainties in wall thickness estimation, for which our results show large variability, between patients but also between measurement methods. Our results also show a large variability in ultimate stress, a value which can hardly be obtained non-invasively. In order to infer a patient-specific estimate of this value, a statistical multiple regression analysis should be performed on a vast dataset of ultimate stress values related to clinically relevant patient data.

Acknowledgements The authors would like to thank Liberia Fresiello for generating the aortic pressure waveforms. 
Compliance with Ethical Standards

Funding: This study was funded by a research project (G093211N) of the Research Foundation-Flanders (FWO) and a postdoctoral fellowship of FWO.

Conflict of Interest: The authors declare that they have no conflict of interest.

\section{References}

Azadani AN, Chitsaz S, Mannion A, Mookhoek A, Wisneski A, Guccione JM, Hope MD, Ge L, Tseng EE (2013) Biomechanical Properties of Human Ascending Thoracic Aortic Aneurysms. The Annals of Thoracic Surgery 96(1):50-58, DOI 10.1016/j. athoracsur.2013.03.094

Chau KH, Elefteriades JA (2013) Natural history of thoracic aortic aneurysms: Size matters, plus moving beyond size. Progress in Cardiovascular Diseases 56(1):74-80, DOI 10.1016/j.pcad.2013.05.007

Chow MJ, Zhang Y (2011) Changes in the Mechanical and Biochemical Properties of Aortic Tissue due to Cold Storage. Journal of Surgical Research 171(2):434-442, DOI 10.1016/j.jss.2010.04.007

Davies RR, Gallo A, Coady MA, Tellides G, Botta DM, Burke B, Coe MP, Kopf GS, Elefteriades JA (2006) Novel Measurement of Relative Aortic Size Predicts Rupture of Thoracic Aortic Aneurysms. Ann Thorac Surg 81(1):169-77, DOI 10.1016/j.athoracsur.2005. 06.026

Duprey A, Khanafer K, Schlicht M, Avril S, Williams D, Berguer R (2010) In vitro characterisation of physiological and maximum elastic modulus of ascending thoracic aortic aneurysms using uniaxial tensile testing. European Journal of Vascular and Endovascular Surgery 39(6):700 - 707, DOI http: //dx.doi.org/10.1016/j.ejvs.2010.02.015

Duprey A, Trabelsi O, Vola M, Favre JP, Avril S (2016) Biaxial rupture properties of ascending thoracic aortic aneurysms. Acta Biomaterialia pp -, DOI http://dx.doi.org/10.1016/j.actbio.2016.06.028

Elefteriades JA, Sang A, Kuzmik G, Hornick M (2015) Guilt by association: paradigm for detecting a silent killer (thoracic aortic aneurysm). Open Hear 2(1), DOI 10.1136/openhrt-2014-000169

Fehervary H, Smoljkić M, Vander Sloten J, Famaey N (2016) Planar biaxial testing of soft biological tissue using rakes: a critical analysis of protocol and fitting process. J Mech Behav Biomed Mater DOI 10.1016/ j.jmbbm.2016.01.011

Ferrari G, Kozarski M, Zieliński K, Fresiello L, Di Molfetta A, Górczyńska K, Pałko KJ, Darowski M (2012) A modular computational circulatory model applicable to VAD testing and training. J Artif Organs 15(1):32-43, DOI 10.1007/s10047-011-0606-4
Fillinger MF, Marra SP, Raghavan ML, Kennedy FE (2003) Prediction of rupture risk in abdominal aortic aneurysm during observation: Wall stress versus diameter. J Vasc Surg 37(4):724-732, DOI 10.1067/ mva.2003.213

Fresiello L, Zieliński K, Jacobs S, Di Molfetta A, Pałko KJ, Bernini F, Martin M, Claus P, Ferrari G, Trivella MG, Górczyńska K, Darowski M, Meyns B, Kozarski M (2014) Reproduction of continuous flow left ventricular assist device experimental data by means of a hybrid cardiovascular model with baroreflex control. Artif Organs 38(6):456-468, DOI 10.1111/aor.12178

García-Herrera CM, Atienza JM, Rojo FJ, Claes E, Guinea GV, Celentano DJ, García-Montero C, Burgos RL (2012) Mechanical behaviour and rupture of normal and pathological human ascending aortic wall. Med Biol Eng Comput 50(6):559-566, DOI 10.1007/s11517-012-0876-x

Gasser TC, Ogden RW, Holzapfel GA (2006) Hyperelastic modelling of arterial layers with distributed collagen fibre orientations. J R Soc Interface 3(6):15-35, DOI 10.1098/rsif.2005.0073

Gasser TC, Auer M, Labruto F, Swedenborg J, Roy J (2010) Biomechanical Rupture Risk Assessment of Abdominal Aortic Aneurysms : Model Complexity versus Predictability of Finite Element Simulations. Eur J Vasc Endovasc Surg 40(2):176-185, DOI 10. 1016/j.ejvs.2010.04.003

Haskett D, Johnson G, Zhou A, Utzinger U, Vande Geest J (2010) Microstructural and biomechanical alterations of the human aorta as a function of age and location. Biomech Model Mechanobiol 9(6):725736, DOI 10.1007/s10237-010-0209-7

Iliopoulos DC, Kritharis EP, Giagini AT, Papadodima SA, Sokolis DP (2009) Ascending thoracic aortic aneurysms are associated with compositional remodeling and vessel stiffening but not weakening in age-matched subjects. J Thorac Cardiovasc Surg 137(1):101-109, DOI 10.1016/j.jtcvs.2008.07.023

Joldes GR, Miller K, Wittek A, Doyle BJ (2015) A simple, effective and clinically applicable method to compute abdominal aortic aneurysm wall stress. Journal of the Mechanical Behavior of Biomedical Materials pp 1-10, DOI 10.1016/j.jmbbm.2015.07. 029

Khanafer K, Duprey A, Zainal M, Schlicht M, Williams D, Berguer R (2011) Determination of the elastic modulus of ascending thoracic aortic aneurysm at different ranges of pressure using uniaxial tensile testing. J Thorac Cardiovasc Surg 142(3):682-686, DOI 10.1016/j.jtcvs.2010.09.068 
Koullias G, Modak R, Tranquilli M, Korkolis DP, Barash P, Elefteriades JA (2005) Mechanical deterioration underlies malignant behavior of aneurysmal human ascending aorta. J Thorac Cardiovasc Surg 130(3):677, DOI 10.1016/j.jtcvs.2005.02.052

Krishnan K, Ge L, Haraldsson H, Hope MD, Saloner DA (2015) Ascending thoracic aortic aneurysm wall stress analysis using patient-specific finite element modeling of in vivo magnetic resonance imaging. Interactive CardioVascular and Thoracic Surgery 21(July):471-480, DOI 10.1093/icvts/ivv186

Martin C, Sun W, Pham T, Elefteriades J (2013a) Predictive biomechanical analysis of ascending aortic aneurysm rupture potential. Acta Biomaterialia 9(12):9392-9400, DOI 10.1016/j.actbio.2013.07.044

Martin C, Sun W, Primiano C, McKay R, Elefteriades J (2013b) Age-Dependent Ascending Aorta Mechanics Assessed Through Multiphase CT. Ann Biomed Eng 41(12):1199-1216, DOI 10.1016/j.micinf.2011.07.011. Innate

Martufi G, Gasser TC, Appoo JJ, Di Martino ES (2014) Mechano-biology in the thoracic aortic aneurysm: a review and case study. Biomechanics and Modeling in Mechanobiology 13(5):917-928, DOI 10.1007/ s10237-014-0557-9

Martufi G, Forneris A, Appoo JJ, Di Martino ES (2015) Is There a Role for Biomechanical Engineering in Helping to Elucidate the Risk Profile of the Thoracic Aorta? Annals of Thoracic Surgery 101(1):390-398, DOI 10.1016/j.athoracsur.2015.07.028

Nichols M, Townsend N, Scarborough P, Rayner M (2012) European Cardiovascular Disease Statistics 2012. September, DOI 978-2-9537898-1-2

Niestrawska JA, Cohnert TU, Holzapfel GA (2016) Mechanics and Microstructure of Healthy Human Aortas and AAA Tissues : Experimental Analysis and Modeling. In: ECCOMAS Congress 2016

Ogden RW (2009) Anisotropy and Nonlinear Elasticity in Arterial Wall Mechanics. In: Holzapfel GA, Ogden RW (eds) Biomech. Model. Mol. Cell. Tissue Levels, vol 508, Springer Vienna, pp 179-258, DOI 10.1007/ 978-3-211-95875-9 $\ \_3$

Okamoto RJ, Xu H, Kouchoukos NT, Moon MR, Sundt TM (2003) The influence of mechanical properties on wall stress and distensibility of the dilated ascending aorta. J Thorac Cardiovasc Surg 126(3):842-850, DOI 10.1016/S0022-5223(03)00728-1

Pape LA, Tsai TT, Isselbacher EM, Oh JK, O'Gara PT, Evangelista A, Fattori R, Meinhardt G, Trimarchi S, Bossone E, Suzuki T, Cooper JV, Froehlich JB, Nienaber CA, Eagle KA (2007) Aortic Diameter $>=5.5 \mathrm{~cm}$ Is Not a Good Predictor of
Type A Aortic Dissection: Observations From the International Registry of Acute Aortic Dissection (IRAD). Circulation 116(10):1120-1127, DOI 10. 1161/CIRCULATIONAHA.107.702720

Pasta S, Phillippi JA, Tsamis A, D'Amore A, Raffa GM, Pilato M, Scardulla C, Watkins SC, Wagner WR, Gleason TG, Vorp DA (2015) Constitutive modeling of ascending thoracic aortic aneurysms using microstructural parameters. Med Eng Phys 000(January 2016):1-10, DOI 10.1016/j.medengphy. 2015.11.001

Pierce DM, Maier F, Weisbecker H, Viertler C, Verbrugghe P, Famaey N, Fourneau I, Herijgers P, Holzapfel GA (2015) Human thoracic and abdominal aortic aneurysmal tissues: Damage experiments, statistical analysis and constitutive modeling. J Mech Behav Biomed Mater 41:92-107, DOI 10.1016/j. jmbbm.2014.10.003

Raghavan ML, Hanaoka MM, Kratzberg JA, Lourdes MD, Simao E (2011) Biomechanical failure properties and microstructural content of ruptured and unruptured abdominal aortic aneurysms. Journal of Biomechanics 44(13):2501-2507, DOI 10.1016/j. jbiomech.2011.06.004

Shang EK, Nathan DP, Sprinkle SR, Vigmostad SC, Fairman RM, Bavaria JE, Gorman RC, Gorman JH, Chandran KB, Jackson BM (2013) Peak wall stress predicts expansion rate in descending thoracic aortic aneurysms. Ann Thorac Surg 95(2):593-598, DOI 10.1016/j.athoracsur.2012.10.025

Sinnecker T, Mittelstaedt P, Do J (2012) Multiple Sclerosis Lesions and Irreversible Brain Tissue Damage. Arch Neurol 69(6):739-745, DOI 10.1001/ archneurol.2011.2450

Smoljkić M, Vander Sloten J, Segers P, Famaey N (2015) Non-invasive, energy-based assessment of patient-specific material properties of arterial tissue. Biomechanics and Modeling in Mechanobiology 14(5):1045-1056

Sommer G, Sherifova S, Oberwalder PJ, Dapunt OE, Ursomanno PA, DeAnda A, Griffith BE, Holzapfel GA (2016) Mechanical strength of aneurysmatic and dissected human thoracic aortas at different shear loading modes. Journal of Biomechanics pp -, DOI http://dx.doi.org/10.1016/j.jbiomech.2016.02.042

Stemper BD, Yoganandan N, Stineman MR, Gennarelli TA, Baisden JL, Pintar FA (2007) Mechanics of Fresh, Refrigerated, and Frozen Arterial Tissue. Journal of Surgical Research 139:236-242, DOI 10. 1016/j.jss.2006.09.001

Trabelsi O, Davis FM, Rodriguez-Matas JF, Duprey A, Avril S (2015) Patient specific stress and rupture analysis of ascending thoracic aneurysms. Journal 
of Biomechanics 48(10):1836-1843, DOI 10.1016/j. jbiomech.2015.04.035

Trablesi O, Duprey A, Favre JP, Avril S (2016) Predictive Models with Patient Specific Material Properties for the Biomechanical Behavior of Ascending Thoracic Aneurysms. Annals of Biomedical Engineering 44(1):84-98, DOI 10.1007/s10439-015-1374-8

Vande Geest JP, Di Martino ES, Bohra A, Makaroun MS, Vorp Da (2006) A biomechanics-based rupture potential index for abdominal aortic aneurysm risk assessment: Demonstrative application. Annals of the New York Academy of Sciences 1085:11-21, DOI 10. 1196/annals.1383.046

Venkatasubramaniam AK, Fagan MJ, Mehta T, Mylankal KJ, Ray B, Kuhan G, Chetter IC, McCollum PT (2004) A comparative study of aortic wall stress using finite element analysis for ruptured and non-ruptured abdominal aortic aneurysms. Eur J Vasc Endovasc Surg 28(2):168-176, DOI 10.1016/ j.ejvs.2004.03.029

Venkatasubramanian RT, Grassel ED, Barocas VH, Lafontaine D, Bischof JC (2006) Effects of Freezing and Cryopreservation on the Mechanical Properties of Arteries. Annals of Biomedical Engineering 34(5):823-832, DOI 10.1007/s10439-005-9044-x

Vorp DA, Schiro BJ, Ehrlich MP, Juvonen TS, Ergin MA, Griffith BP (2003) Effect of aneurysm on the tensile strength and biomechanical behavior of the ascending thoracic aorta. Ann Thorac Surg 75(4):1210-1214, DOI 10.1016/S0003-4975(02) 04711-2

Weisbecker H, Pierce DM, Regitnig P, Holzapfel GA (2012) Layer-specific damage experiments and modeling of human thoracic and abdominal aortas with non-atherosclerotic intimal thickening. Journal of the Mechanical Behavior of Biomedical Materials 12:93-106, DOI 10.1016/j.jmbbm.2012.03.012

Xiong J, Wang M, Zhou W, Wu JG (2008) Measurement and analysis of ultimate mechanical properties, stress-strain curve fit, and elastic modulus formula of human abdominal aortic aneurysm and nonaneurysmal abdominal aorta. Journal of Vascular Surgery 48(1):189-195, DOI 10.1016/j.jvs.2007.12. 053 